\title{
A Study on the Imaginability of Settlement Space Environment in Ethnic Areas-Taking Ji'na Qiang Village as an Example
}

\author{
Yue Chen \\ Southwest Minzu University, Chengdu, China \\ Email: 4063853@qq.com
}

How to cite this paper: Chen, Y. (2020) A Study on the Imaginability of Settlement Space Environment in Ethnic AreasTaking Ji'na Qiang Village as an Example. Open Access Library Journal, 7: e6925. https://doi.org/10.4236/oalib.1106925

Received: October 23, 2020

Accepted: November 6, 2020

Published: November 9, 2020

Copyright $\odot 2020$ by author(s) and Open Access Library Inc.

This work is licensed under the Creative Commons Attribution International License (CC BY 4.0).

http://creativecommons.org/licenses/by/4.0/

\begin{abstract}
This paper analyzes the spatial environment image of Ji'na Qiang village by using the methods of questionnaire survey, interview description, cognitive map, and selecting five basic elements: road, boundary, region, node and landmark. To provide relevant suggestions for the protection and renewal of settlement space in ethnic areas.
\end{abstract}

\section{Subject Areas}

Architecture, Culture

\section{Keywords}

Cognitive Map, Environmental Image, Ji'na Qiang Village

\section{The Theory of City Image}

Image is a psychological image established by people about the environment they have experienced, and it can also become a psychological impression [1]. Impression is the product of a two-way process between the observer and his space environment. In the 1960s, Kevin Lynch, an American urban planning expert, put forward the concept of "city image" and published the book "city image", which studies the form of urban space from the perspective of environmental perception and human behavior. The elements of city image are summarized into five kinds, namely, region, road, boundary, node and landmark. Based on previous studies, this paper studies the imaginability of the settlement space of Ji'na Qiang village through questionnaire survey, cognitive map and other 
methods.

\section{The Research Background of the Spatial Environment Image of Ji'na Qiang Village Settlement}

Beichuan is the Qiang nationality settlement and the only Qiang Autonomous County in China. The Qiang villages in the county have always shown the unique regional cultural characteristics and Qiang style amorous feelings of the Qiang nationality area. In recent years, with the development of tourism in Beichuan County, the construction and improvement of Ji'na Qiang Village have changed its original environmental image, which has a great impact on its future development and the protection and inheritance of Qiang traditional culture. Therefore, it is of great significance to study the environmental image of settlement space in Ji'na Qiangzhai.

\section{Research Methods}

Based on Kevin Lynch's theory of city image, this paper adopts the combination of questionnaire survey, interview description and cognitive map to synthesize the problems existing in the various elements of the spatial environment image of Ji'na Qiang village.

\subsection{Questionnaire Survey}

This study makes an on-the-spot investigation of Ji'na Qiang village, starts with different people, understands the problems in its environmental image, finds out the parts that may be ignored, and obtains the content of the questionnaire survey by synthesizing the opinions of the people who collect the house. In this survey, villagers of different ages and occupations were randomly selected to distribute questionnaires and interviews. A total of 100 copies were sent out and 95 were recovered. The effective rate of the questionnaire was $95 \%$.

\subsection{Cognitive Map}

Cognitive map is a local image formed by people in different environments and experiences based on their own consciousness, and their respective "cognitive maps" are drawn through points, lines and surfaces. The superimposed "cognitive maps" are people's consensus on the image of the region. In this study, interviewees were asked to draw a map of the area they were familiar with, and mark the buildings, road names, nodes and so on.

\subsection{Interview Description}

The interview description can know the direct reaction of the residents to the village, as well as the unconcerned problems in the village, which can often bring a new breakthrough to this research. The interviewees are mainly villagers who have lived in Ji'na Qiang Village for a long time. 


\section{Analysis of the Spatial Environment Image of Ji'na Qiang Village}

\subsection{Results of the Questionnaire}

This questionnaire survey comprehensively analyzes the spatial environment images of Ji'na Qiang village, the overall situation is as follows.

1) It can be seen from Table 1 that $72 \%$ of the villagers think that Diaolou is the most distinctive feature of the traditional Qiang culture in Beichuan, which is the landmark of Ji'na Qiang village. On the other hand, it can be seen that the inheritance of the traditional Qiang intangible culture in Ji'na Qiang village is poor, in which the Qiang embroidery culture, which can represent the Qiang culture, has not been mentioned by the villagers. 2) It can be seen from Table 2 that the direction of the villagers for the landmark buildings is not very obvious. The villagers who choose the towers account for $13 \%$, while the proportion of going to the riverside landscape belt and cultural square is relatively high. It shows that the villagers have a high demand for leisure activities. 3) It can be seen from Table 3 that the villagers pay more attention to the problems of living conditions, living environment and infrastructure, indicating that the villagers pay more attention to the regional living environment, which is also closely related to the villagers' life.

In the survey of the overall description of the Gina Qiang village, the respondents held a conservative attitude towards all kinds of descriptions of the Qiang village, indicating that people's impression that the traditional Qiang cultural characteristics of the Ji'na Qiang village did not fully show. Generally speaking, Ji'na Qiangzhai villagers pay more attention to the image elements of Qiang village space environment, but due to the relatively slow economic and cultural development and construction, the construction of traditional Qiang characteristics in Ji'na Qiang village is insufficient. Residential buildings, landscape

Table 1. Selection of landmark buildings in Ji'na Qiang village.

\begin{tabular}{cccccc}
\hline Name & Diaolou & $\begin{array}{c}\text { Cultural } \\
\text { Square }\end{array}$ & $\begin{array}{c}\text { Visitor } \\
\text { Center }\end{array}$ & $\begin{array}{c}\text { Residential } \\
\text { Building }\end{array}$ & $\begin{array}{c}\text { Qiangzhai } \\
\text { Entrance }\end{array}$ \\
\hline Percentage (\%) & 72 & 16 & 2 & 6 & 3 \\
\hline
\end{tabular}

Table 2. Selection of places you most want to visit at the weekend.

\begin{tabular}{cccccc}
\hline Name & $\begin{array}{c}\text { Riverside } \\
\text { Landscap }\end{array}$ & $\begin{array}{c}\text { Cultural } \\
\text { Square }\end{array}$ & $\begin{array}{c}\text { Pedestrian } \\
\text { mall }\end{array}$ & $\begin{array}{c}318 \mathrm{RV} \\
\text { Club }\end{array}$ & Diaolou \\
\hline Percentage (\%) & 47 & 25 & 7 & 8 & 13 \\
\hline
\end{tabular}

Table 3. Problems existing in Ji'na Qiang village.

\begin{tabular}{cccccc}
\hline Name & $\begin{array}{c}\text { The house } \\
\text { is leaking }\end{array}$ & $\begin{array}{c}\text { Traffic } \\
\text { jam }\end{array}$ & $\begin{array}{c}\text { The commercial street } \\
\text { is underdeveloped. }\end{array}$ & $\begin{array}{c}\text { Few kinds of } \\
\text { landscape }\end{array}$ & Other \\
\hline Percentage (\%) & 62.75 & 5.08 & 13.5 & 10.93 & 7.74 \\
\hline
\end{tabular}


greening, commerce and other infrastructure construction need to be updated and improved. At the same time, for the inheritance and development of Beichuan traditional Qiang culture, Jina Qiang Village should strengthen the intangible cultural heritage, such as Qiang Embroidery, Guozhuang Dance, Qiang Festivals, as well as the development and construction of local folk customs.

\subsection{Result Analysis of Cognitive Map}

Cognitive map is that people are stimulated by the surrounding environment for a long time, form memory to the characteristic information of the surrounding environment, is the representation product of the local environment, and is the most basic method to study the city image. In this study, a more detailed cognitive map of Ji'na Qiang Village was drawn from the survey (As shown in Figure 1).

Since the Ji'na Qiang village is built in the accumulation area of the trumpet-shaped impact ditch on the side of the Subao River, that is, the area where the mountain meets the river, the slope of the land in this area is relatively large, so the driveway is built in the shape of "Zhi". Starting from the bridgehead, the inner and outer ring road is formed along the Subao River and Xiangshui ditch through the whole Qiang village, and the extended branch road from the ring road leads to every household. Constitute the primary and secondary, vertical and horizontal orderly village traffic space [2]. In addition, the characteristic landscape trail and the Qiang-style plank road across the Xiangshui ditch form

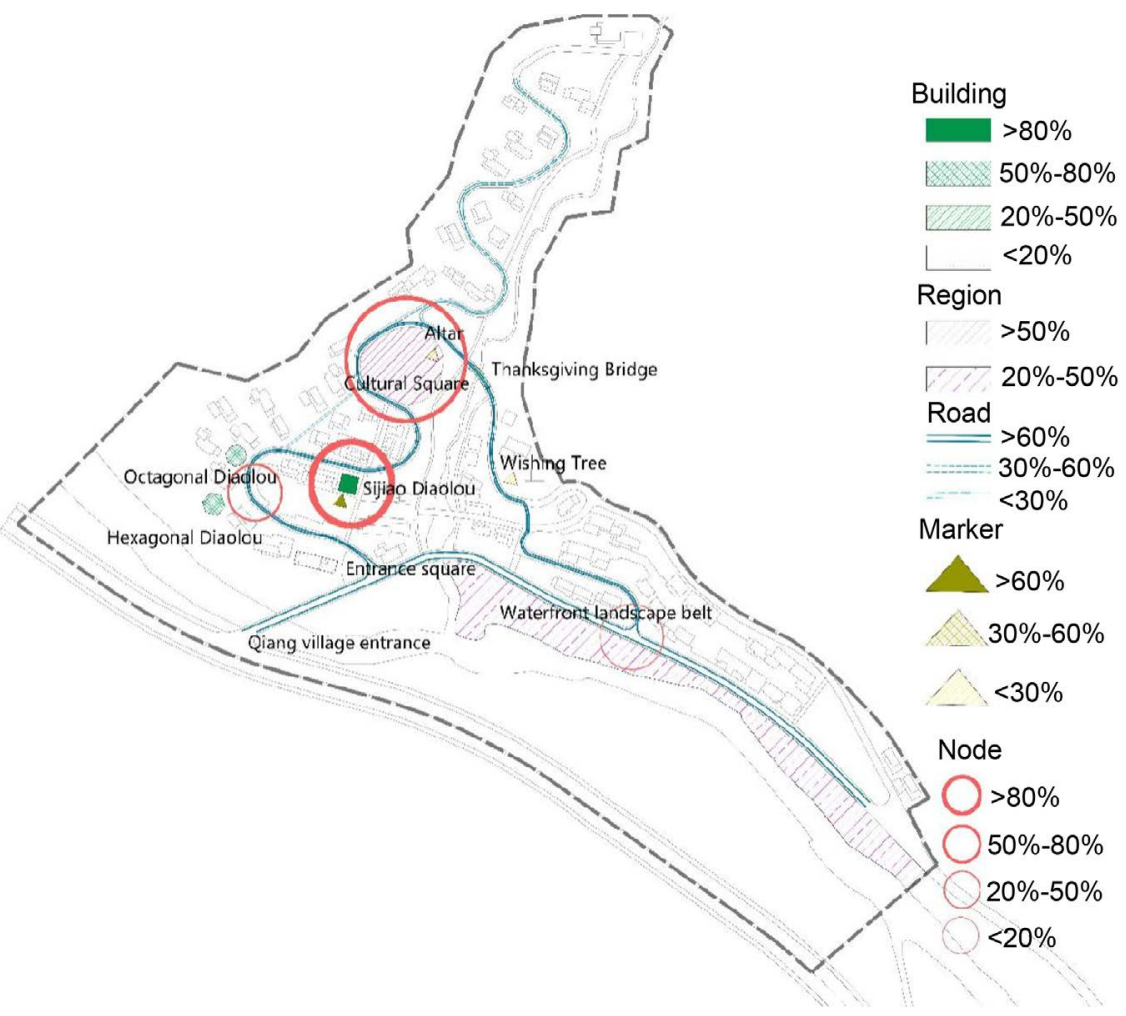

Figure 1. Cognitive map of Ji'na Qiang village. 
an internal walkway, and these three levels of road system constitute the framework of the internal construction of Ji'na Qiang village [3].

From the cognitive map of Ji'na Qiangzhai, we can see that: 1) From the entrance of Qiangzhai to the waterfront landscape belt through the cultural square to form a loop, people have a high degree of recognition. On the other hand, people have a low degree of understanding of the road from the Culture Square to the folk houses in the north of Qiangzhai. 2) From the perspective of architectural cognition, people have a relatively high degree of understanding of the towers, in which Sijiao Diaolou is regarded by the villagers as the symbol of Ji na Qiang village, followed by the Qiang altar. Among them, the location of Sijiao Diaolou is also the node with the highest degree of cognition in Ji'na Qiang Village. 3) The buildings with high cognitive degree of landmarks and nodes are mainly distributed on the roads with high cognitive degree. 4) From the regional point of view, the cognitive degree of the cultural square is higher, followed by the waterfront landscape belt. Therefore, landmarks, nodes and roads are important factors that affect the level of public awareness. The establishment of signs and nodes promotes the formation of roads, and through interaction and interrelation, they jointly establish the cognitive map of Jina Qiang Village in people's impression.

\section{Opinions on Strengthening the Spatial Environment Image of Ji'na Qiang Village}

This paper makes an image analysis of the space environment of Ji'na Qiang village, and mainly expounds the characteristics of the space environment image of Jina Qiang village from five aspects: road, landmark, node, region and architecture. Among them, the road, as an important element of the Qiang village image, is the skeleton of the Qiang village image, in which the trunk road appears more frequently. From the analysis of the cognitive map of Jina Qiangzhai, from the entrance of Qiangzhai connected to the waterfront landscape belt through the cultural square to form a ring road, people have a high degree of recognition, in which the buildings, nodes and signs with high recognition are also distributed on this ring road, it is not difficult to see that buildings, nodes and signs play a role in promoting the degree of road cognition. Therefore, the construction of characteristic buildings and nodes in the north of Qiangzhai can enhance the awareness of the road. From the analysis of buildings, nodes and landmarks with a higher degree of cognition, it can be found that the more obvious the performance of traditional Qiang culture is, the higher the degree of cognition is. Therefore, the further excavation and construction of the traditional Qiang culture of Ji'na Qiang village is helpful to improve the image of Qiang village.

To sum up, the imagery of the space environment of Jina Qiang Village is the result of the synthesis of various image elements, and the five elements often influence each other and cannot be distinguished separately. While improving the image of the settlement space environment of Qiang village, it is also conducive 
to the inheritance and protection of traditional Qiang culture, and plays a role in promoting the renewal and development of Ji'na Qiang village in the future.

\section{The Factors Influencing the Formation of Environmental Image in Settlement Space in Ethnic Minority Areas}

The environmental image of settlement space in ethnic minority areas is often influenced by subjective and objective factors in the process of formation. Under the influence of both, the image structure of settlement space environment is more diversified. From the analysis of objective factors, the formation of the environmental image of settlement space depends on the cultural, political, economic and other physical factors of the region. Compared with the Han area, the nodes, landmarks and buildings with the characteristics of the Qiang nationality have a stronger influence on the image of the space environment. From the analysis of subjective factors, due to the different gender, age, education level and occupation of the evaluation subject, the attention and demand direction of the Qiang village image are also different, which also affects the research conclusion.

\section{Summary}

Under the joint action of the "miraculous craftsmanship" of nature and the rich and colorful culture of the ancient Qiang nationality, Ji'na Qiang Village has formed a very unique form of settlement space. The research on the imaginability of the settlement space of Ji'na Qiang village is of great significance for understanding, protecting and developing the humanistic environment of the ancient Qiang traditional settlement space, regulating the man-land relationship in modern cities and creating a good living environment.

1) Understanding, Development and Protection of traditional settlement Space

Under the dual effects of natural disasters and man-made development, it hinders the inheritance and development of the traditional culture of ancient Qiang. It is not easy to show the cultural connotation of the traditional settlement space. Although the modern urban spatial image theory cannot be fully integrated with the traditional humanistic connotation, it has a certain reference value to use the image theory framework to study the image form of Ji'na Qiang settlement space and analyze the reasons for the formation of image elements.

With the promotion of the new urbanization mechanism, the space and functional structure of the settlement are affected by modern architectural methods and elements. Through the study of the imaginability of the settlement space, abstract symbols are used to show the humanistic connotation of the traditional settlement. It is of great significance to the development of traditional culture [4].

2) The Regulation of Man-Land relationship in Modern cities

The settlement space of Jina Qiang village is the expression of the connota- 
tion of ancient Qiang culture and reflects the adaptability of traditional culture to the modern social environment. Kevin Lynch's city image theory ignores the role of culture in linking and merging various spatial elements. Modern urban construction pays more attention to the role of human beings, neglecting the coordination between human and land, which leads to "urban disease". On the other hand, the traditional settlement can reasonably deal with the relationship between man and land and blend with nature [5]. The site selection and layout of Ji'na Qiang Village all follow the Fengshui requirements of "facing mountains and rivers" and accord with the concept of "unity of man and nature". These play an important role in solving the problems caused by the "rough" development mode of modern cities.

3) Inspiration for the creation of a good living environment

Modern people increasingly pursue the quality of life and living environment, but ignore the inheritance of traditional settlements in the process of urban construction, living in the same city. Therefore, it is particularly important to improve the image and identifiability of the city.

Each city has its own unique image, which is the connection between historical and modern development. The inheritance of tradition does not rely on the traditional style pieced together by sporadic ancient buildings and scattered image symbols, let alone a simple imitation of tradition. The settlement of Ji'na Qiang Village has a unique regional landscape, and the method of perfect integration of traditional and modern is worth learning and using for reference. Tradition is not a simple material, but a connotation, so the inheritance of tradition is reflected not only in the material environment, but also in the spiritual agreement between ancient and modern times [6].

\section{Acknowledgements}

This study was awarded the graduate innovation project of southwest Minzu University (No. CX2019SZ06) support.

\section{Conflicts of Interest}

The author declares no conflicts of interest regarding the publication of this paper.

\section{References}

[1] (USA) Lynch, K. (2001) Image of the City. Translated by Fang, Y.P. and He, X.J. Huaxia Publishing House, Beijing.

[2] Tan, Z.K. and Sings, B. (2007) A Brief Analysis of the Morphological Characteristics and Origin of the Traditional Qiang Village Settlement. Shanxi Architecture, No. 10, 32-33.

[3] Gao, Y.Q. (2016) Study on the Spatial Characteristics of Settlement Landscape of Qiang Village in Beichuan. Master's Thesis, Southwest University, Chongqing.

[4] Gu, C.L. and Song, G.C. (2001) Study on the Space and Constituent Elements of Beijing City Image. Acta Geographica Sinica, 56, 64-74. 
[5] Feng, J.B. (2005) Spatial Perception and Image Spatial Structure of Beijing Urban Residents. Geoscience, 25, 142-154.

[6] Liu, Y.F. (2005) Taking Wuhan as an Example to Discuss Urban Image and Urban Design. Science and Technology of Western China, No. 3, 32-33. 